\title{
ELABORAÇÃO E ANÁLISE DE ORÇAMENTO EMPRESARIAL EM INDÚSTRIA DE ESQUADRIAS
}

\author{
Fernando Heineck ${ }^{1}$, Alexandre André Feil ${ }^{2}$ \\ ${ }^{1,2}$ Universidade do Vale do Taquari (UNIVATES) \\ 1 fheuniverso.univates.br \\ 2 alexandre.feillegmail.com
}

\section{Resumo}

O orçamento empresarial elaborado com base nos objetivos empresariais pode representar o diferencial competitivo das Micro e Pequenas Empresas (MPE). Neste contexto, este estudo objetiva elaborar e analisar o orçamento empresarial em MPE indústria de esquadrias, neste estudo denominada de Alfa. A metodologia empregada vincula-se a pesquisa quantitativadescritiva, utilizando o procedimentos técnico de estudo de caso por meio de pesquisa documental e entrevista não estruturada. A elaboração do orçamento permitiu visualizar a evolução da eficiência econômica da indústria Alfa no período orçado, em especial, no período posterior ao investimento planejado na ampliação de infraestrutura. Os principais resultados revelam que a elaboração do orçamento da indústria Alfa deve observar as características específicas do porte MPE, em especial, as relacionadas as limitações dos recursos financeiros, mão de obra e o tempo disponível. Além disso, a previsão futura deve ser realizada com prudência e cautela, por meio de um orçamento flexível para adaptar-se as mudanças de mercado. A avaliação do orçamento projetado preserva a saúde financeira, patrimonial e econômica da indústria alfa no período de 2017 a 2021. Portanto, conclui-se que a elaboração e análise do orçamento na indústria de esquadria Alfa apresenta uma contribuição em direção a implementação das práticas adequadas ao seu uso e performance.

Palavra-chave: Planejamento. Micro e pequenas empresas. Orçamento empresarial.

\section{ESTABLISHMENT AND ANALYSIS OF BUSINESS BUDGET IN MITER INDUSTRY}

\begin{abstract}
The business budget based on business objectives can represent the competitive advantage of Micro and Small Enterprises (SMES). In this context, this study aims to elaborate and analyze the business budget in MPE industry of frames, in this study called Alfa. The methodology employed is linked to the quantitative-descriptive research, using the technical procedures of case study through documentary research and unstructured interview. The elaboration of the budget allowed to visualize the evolution of the economic efficiency of the Alpha industry in the budgeted period, especially in the period after the planned investment in the expansion of infrastructure. The main results show that the budgeting of the Alpha industry must observe the specific characteristics of the MEP, in particular those related to the limitations of financial resources, labor and time available. In addition, future forecasting should be carried out with caution and caution, through a flexible budget to adapt to market changes. The evaluation of the projected budget preserves the financial, assets and economic health of the alpha industry in the period from 2017 to 2021. Therefore, it is concluded that the elaboration and analysis of
\end{abstract}


the budget in the alpha miter industry presents a contribution towards the implementation of the appropriate practices to its use and performance.

Keyword: Planning. Micro and small enterprises. business budget.

\section{Introdução}

$\mathrm{Na}$ atualidade as corporações operam com margens de lucro cada vez menores, e pequenos detalhes ou erros no gerenciamento podem provocar prejuízos e dificuldades financeiras, comprometendo a saúde econômica do negócio e, em alguns casos, até a sua continuidade. A melhoria do gerenciamento pode ocorrer por meio do planejamento empresarial, auxiliando o gestor na definição dos objetivos, metas e tomadas de decisões.

O planejamento corporativo deve ser alicerçado pelo orçamento, que consiste em uma ferramenta básica de gestão (SANVICENTE; SANTOS, 2008). Sebrae (2013) enfatiza que as Micro e Pequenas Empresas (MPE) enfrentam os mesmos obstáculos operacionais e gerenciais que as médias e grandes. Portanto, o orçamento não reserva-se apenas às médias e grandes empresas, mas também as MPE, pois proporciona uma visão de futuro, capaz de confrontar o desempenho entre projeções e resultados alcançados (WELSCH, 2010; OLBERMANN; FEIL; SCHREIBER, 2014). Além disso, corrige eventuais desvios ou desequilíbrios antes de causarem graves danos financeiros ao negócio (SANVICENTE; SANTOS, 2008).

As críticas ao orçamento empresarial referentes a problemas de utilização e execução estão relacionados ao alto custo, ausência de geração de valor, desconexão com o ambiente competitivo e encorajamento de comportamentos antiéticos (HOPE; FRASER, 2003; VAZNONIENE, 2012). Sá (2014) ainda complementa as dificuldades com o tratamento das variáveis intangíveis - controla apenas o que pode ser medido - e a imprecisão das projeções orçamentárias. Entretanto, Libby e Murray (2010) apontam que os sistemas orçamentários desempenham um papel fundamental no sistema de controle, auxiliando na implantação das estratégias. Além disso, as empresas não tem planos de abandonar a prática orçamentária e planejam medidas para melhorar seus sistemas e superar suas críticas (VAZNONIENE, 2012).

A utilização de um sistema orçamentário oferece vantagens às empresas, pois formaliza seus desempenhos esperados, identifica pontos de eficiência ou ineficiência produtiva, fixa objetivos e avalia fatores relevantes que precedem a tomada de decisões (MARTH; FEIL, 2014a). Neste contexto, este estudo objetiva elaborar e analisar o orçamento empresarial adequado as especificidades das MPE (indústria e comércio de esquadrias).

Este estudo justifica-se em função da MPE apresentar como principais fatores de insucesso os problemas financeiros e a falta de conhecimento gerencial (SEBRAE, 2013). Sendo assim, nas MPE nacionais o uso de ferramentas de gestão é esporádica, pois os modelos de gestão são formatados para utilização em grandes organizações. A utilização do orçamento empresarial em MPE facilita a coordenação das atividades pelos gestores, promove a responsabilidade, facilita o controle e contribui com metas claras e precisas (DAVILA; FOSTER; LI, 2009). Ademais, promove a eficiência por meio do planejamento e da comparação dos dados orçados (planejados) frente aos reais (realizados) (HANSEN; OTLEY; VAN DER STEDE, 2003). King, Clarkson e Wallace (2010) enfatizam que as organizações necessitam implementar uma prática formal de orçamento, observando critérios e métodos apropriados. Portanto, este estudo contribui na práxis com a apresentação de uma forma adequada de elaboração de um orçamento empresarial relacionado ao planejamento estratégico, em funções das dificuldades e da geração de lucratividade. 


\section{REAVI}

\section{Referencial teórico}

\subsection{Panorama brasileiro da MPE}

As MPE representam uma parcela importante no cenário econômico nacional. A pesquisa divulgada pelo Sebrae (2013) revela que este segmento constitui 99\% do total de empresas do país, geram $25 \%$ do Produto Interno Bruto (PIB), são responsáveis por $52 \%$ dos empregos formais, por $40 \%$ da massa salarial e pela geração de $70 \%$ das novas vagas de empregos.

A criação de novas empresas vem ganhando impulso em todo território nacional e este crescimento associado a uma melhora na competitividade por meio dos planejamentos e controles gerenciais tende a gerar impactos positivos na economia (SEBRAE, 2013). Apesar desse cenário, os administradores das MPE nem sempre conseguem gerir adequadamente o negócio em decorrência da ausência de conhecimentos gerenciais básicos e/ou aprofundados, atuando de forma empírica e sem planejamento (DORNELAS, 2012).

Neste sentido, outro aspecto apontado por Chiavenato (2008) refere-se à cautela que os novos empresários devem observar em relação às possíveis causas de insucesso nos novos negócios para evitá-las ou neutralizá-las e impedir que venham prejudicá-lo no futuro. O autor ainda descreve como principais fatores de insucesso empresarial a inexperiência $(72 \%)$, os fatores econômicos $(20 \%)$, as vendas insuficientes (11\%), as despesas excessivas ( $8 \%)$ e outras causas (3\%). Uma pesquisa divulgada pelo Sebrae (2007) concluiu que 55\% dos empresários consideraram as falhas gerencias como a principal dificuldade na condução das atividades do negócio, enquanto que $68 \%$ dos empresários cujas atividades foram encerradas também citaram estas falhas gerenciais como principal motivo.

A amenização dos efeitos nocivos que estas deficiências podem causar ao negócio pode ser alcançada por meio da utilização de ferramentas gerenciais, por exemplo, o planejamento empresarial (SANVICENTE; SANTOS, 2008). O planejamento, além de apoiar-se nas limitações e oportunidades apresentadas pelos recursos da empresa e pelo ambiente externo, tem como base padrões de desempenhos e alvos de atuação considerados desejáveis pelo proprietário ou gestores (WELCH, 2010).

\subsection{Planejamento e orçamento empresarial}

O planejamento empresarial é um enfoque essencial para que o gestor gerencie as atividades com antecedência e use técnicas apropriadas para garantir a coordenação e controle das operações (WELSCH, 2010). O planejamento subdivide-se nas fases de (PADOVEZE, 2005): a) planejamento estratégico: é a etapa inicial do processo de gestão na qual são definidas as políticas, diretrizes e os objetivos, de acordo com leituras de cenários do ambiente endógeno e exógeno; e b) planejamento operacional: no qual são definidos os planos, políticas e objetivos capazes de implantar, no nível operacional da empresa, as diretrizes definidas no planejamento estratégico, por meio da programação, execução e controle.

O prazo coberto pelo planejamento e a frequência que é revisto tem dois enfoques principais (WELSCH, 2010): a) no planejamento periódico: o período é de curto prazo (com base no exercício fiscal), e para o período de longo prazo (cinco anos) e suas revisões são realizadas anualmente, em especial, nos três últimos meses do ano; e b) Planejamento contínuo: o período de curto prazo é de seis meses ou um ano e as revisões completas são mensais ou trimestrais. As projeções de longo prazo costumam ser de 10 anos e revistas de dois em dois anos.

A implantação de um programa de planejamento é consolidada através do orçamento empresarial. Este orçamento empresarial "[...] é a expressão quantitativa de um plano de ação, 
que se caracteriza como um modelo de programação de atividades" (PADOVEZE, 2009, p. 3). $\mathrm{O}$ orçamento fornece direção e instrução à execução dos planos, sendo um meio para fixar padrões de desempenho, medir resultados reais e orientar a gestão para uma atuação satisfatória (MARTH; FEIL, 2014b).

Os aspectos relevantes que devem ser observados na elaboração deste orçamento relacionam-se ao sistema de apoio (custos, contabilidade societária, folha de pagamento, tributos, entre outros) e de cálculos, por exemplo, softwares, planilhas eletrônicas, entre outros (PADOVEZE, 2009). As peças orçamentárias são compostas pelas vendas, produção, despesas operacionais, investimentos, fluxo de caixa e as demonstrações financeiras (QUADRO 1).

\section{Quadro 1 - Peças orçamentárias}

\begin{tabular}{|c|c|}
\hline Peças orçamentárias & Características \\
\hline Orçamento de vendas & $\begin{array}{l}\text { Constitui a projeção de vendas e o ponto de partida do processo orçamentário. Os } \\
\text { métodos de projeção podem ser combinados ou separados, tais como a coleta de } \\
\text { dados das vendas por meio de opiniões de vendedores e administradores e a } \\
\text { projeção por meio de técnicas estatísticas. Devem ser consideradas as limitações } \\
\text { empresariais, a saber, a capacidade de produção, disponibilidade de mão de obra, } \\
\text { adequação de matéria prima e disponibilidade financeira. As estimativas das } \\
\text { vendas podem ser segmentadas por produtos, clientes, regiões e por área de } \\
\text { distribuição, quantidade de vendas à vista e a prazo, as sazonalidades, a } \\
\text { identificação dos impostos sobre vendas e a projeção da inadimplência. }\end{array}$ \\
\hline Orçamento de produção & $\begin{array}{l}\text { Este orçamento é decorrente do orçamento de vendas e abrange a estimativa da } \\
\text { quantidade de produtos que devem ser produzidos para atender as vendas orçadas } \\
\text { e os estoques de produtos acabados. Representa a maior parcela de custos totais, } \\
\text { sendo assim, possui impacto na lucratividade. Inicia-se na definição do nível de } \\
\text { estoque físico ou monetário para os produtos acabados e matérias primas, e } \\
\text { depois segue com a projeção do volume de produção de produtos acabados. O } \\
\text { orçamento de produção abrange os orçamentos de matéria prima, mão de obra e } \\
\text { custos indiretos de produção. }\end{array}$ \\
\hline $\begin{array}{l}\text { Orçamento de despesas } \\
\text { operacionais }\end{array}$ & $\begin{array}{l}\text { Neste orçamento estão vinculadas as despesas administrativas, vendas, tributárias } \\
\text { e financeiras. As despesas administrativas abrangem os gastos que não estão } \\
\text { associados ao processo fabril, por exemplo, pessoal, viagens, telefones, } \\
\text { depreciação, energia elétrica, entre outros. As vendas incluem gastos } \\
\text { relacionados com a área de vendas, distribuição e entrega dos produtos aos } \\
\text { clientes, por exemplo, propaganda, vendedores, fretes, combustível, entre outros. } \\
\text { As tributárias relacionam-se com os tributos referentes as atividades operacionais } \\
\text { e os percentuais devem ser considerados conforme fixados em lei. As despesas } \\
\text { financeiras referem-se aos gastos com captação de recursos financeiros para } \\
\text { capital de giro, capital fixo, entre outros. }\end{array}$ \\
\hline $\begin{array}{l}\text { Orçamento de } \\
\text { investimentos }\end{array}$ & $\begin{array}{l}\text { Consiste na etapa em que a organização consolida suas decisões de investimento, } \\
\text { com aquisições de máquinas, construções, modificações, entre outros. Os } \\
\text { controles e registros de gastos devem ser individualizados principalmente para os } \\
\text { grandes projetos e deve ser considerada a depreciação dos investimentos após sua } \\
\text { instalação e funcionamento. }\end{array}$ \\
\hline $\begin{array}{l}\text { Orçamento do fluxo de } \\
\text { caixa }\end{array}$ & $\begin{array}{l}\text { Instrumento que relacionará os futuros ingressos e desembolsos financeiros } \\
\text { resultantes dos negócios. O conhecimento prévio da existência de possíveis } \\
\text { excedentes ou escassez de recursos financeiros possibilitará a administração } \\
\text { planejar entre captação ou destinação de recursos financeiros com segurança e de } \\
\text { forma rentável. Neste orçamento são necessários alguns ajustes, como exclusão } \\
\text { de itens que não representem saídas efetivas de caixa, como depreciação e } \\
\text { provisões. }\end{array}$ \\
\hline $\begin{array}{l}\text { Projeção das } \\
\text { demonstrações contábeis }\end{array}$ & $\begin{array}{l}\text { A preparação de um orçamento empresarial termina com a projeção da } \\
\text { Demonstração do Resultado do Exercício (DRE) e a projeção do Balanço } \\
\text { Patrimonial (BP), os quais sintetizam e integram os detalhes dos orçamentos, } \\
\text { demonstrando antecipadamente os impactos e resultados dos planos realizados } \\
\text { nas etapas anteriores do orçamento para o período considerado sobre as } \\
\text { características financeiras da empresa. Muitas vezes, poderá ser necessário }\end{array}$ \\
\hline
\end{tabular}


\begin{tabular}{|l|l|}
\hline & $\begin{array}{l}\text { desmanchar, reestudar e reconstruir as alternativas escolhidas em razão de uma } \\
\text { margem de lucro insatisfatória ou uma taxa de retorno sobre o investimento } \\
\text { inadequada. }\end{array}$ \\
\hline
\end{tabular} Fonte: Adaptado de Sanvicente e Santos (2008), Padoveze (2009), Frezatti (2009), Welsch (2010).

Sanvicente e Santos (2008) sustentam que uma das principais vantagens do planejamento orçamentário é a possibilidade de prever por meio da projeção as demonstrações contábeis os resultados financeiros da empresa e realizar diversos testes das prováveis decisões.

\subsection{Análise da projeção das demonstrações contábeis}

A utilização de quocientes para análise complementar das demonstrações contábeis projetadas fornece informações valiosas para múltiplas tomadas de decisão, aumentando o entendimento e a utilidade dos procedimentos orçamentários (WELSCH, 2010). Os principais quocientes relacionam-se a Margem de Contribuição (MC), ao Ponto de Equilíbrio, a Margem de Segurança (MS), ao Earnings Before Interest, Taxes, Depreciation and Amortization (EBITDA), ao Retorno sobre o Ativo (ROA) e ao Retorno sobre o Patrimônio Líquido (ROE).

A MC compreende a diferença entre o preço de venda e a soma dos custos e despesas variáveis (CREPALDI, 2002). Martins (2009, p. 185) salienta que torna "[...] visível a potencialidade de cada produto, mostrando como cada um contribui para, primeiramente, amortizar os gastos fixos e, depois, formar o lucro [...]". Este autor ainda destaca que a MC pode ser tipificada em unitária e total, sendo assim, a unitária define a continuidade ou não de produção de determinado produto, já a total utiliza-se quando há fatores limitantes de produção (máquinas, estrutura física, mão de obra, entre outros) para determinar qual lote de produtos produzir.

O ponto de equilíbrio representa o momento no qual as receitas totais se igualam aos gastos totais, acima deste ponto há lucro e abaixo prejuízo operacional (ASSAF NETO, 2012). Esta ferramenta classifica-se como Ponto de Equilíbrio Contábil (PEC), Ponto de Equilíbrio Econômico (PEE) e Ponto de Equilíbrio Financeiro (PEF) (CREPALDI, 2002). O PEC representa o volume de vendas necessárias para cobrir todos os custos e no qual o lucro é nulo (BRUNI; FAMÁ, 2008). Estes autores (p. 202) definem PEE como “[...] a quantidade de vendas (ou do faturamento) que a empresa deveria obter para poder cobrir a remuneração mínima de capital próprio nela investido [...]". O PEF corresponde à quantidade de vendas totais que se iguala à soma dos gastos que representam desembolso financeiro.

A MS "[...] representa quanto as vendas podem cair sem que a empresa incorra em prejuízo [...]" (CREPALDI, 2002, p. 231). Leone (2010) complementa que também mede a diferença entre o que pode ser produzido e a quantidade apresentada no PEC, demonstrando o espaço que a estrutura produtiva possui para gerar valor econômico.

O EBITDA significa lucro antes dos juros, impostos, depreciação e amortizações e revela o potencial de geração de caixa de um negócio (SILVA, 2012). Este autor ainda destaca que as variações desta ferramenta de um ano para outro demonstram aos investidores se a empresa conseguiu ser economicamente eficiente ou aumentou sua produtividade. O EBITDA não é afetado pelas taxas de juros, regras de depreciação e leis tributárias, o que o torna uma ferramenta útil para comparar uma organização com um concorrente ou segmento de mercado, no entanto, por desconsiderar os efeitos das despesas financeiras com empréstimos sobre o resultado final, não deve ser utilizado isoladamente na análise (CREPALDI, 2012).

O ROA é uma medida que revela o retorno produzido pelos recursos aplicados nos ativos (ASSAF NETO, 2012). Portanto, o lucro gerado pelos ativos (lucro operacional) é aquele antes das despesas financeiras e representa o resultado da atividade econômica independente da origem dos recursos financeiros (ASSAF NETO, 2012). O lucro operacional pertence aos 
acionistas e credores da organização "[...] onde as despesas financeiras são a remuneração devida aos credores e o lucro líquido é a remuneração pertencente aos proprietários" (SALAZAR, 2012, p. 148). Desta forma, o ROA pode ser interpretado como o custo financeiro máximo que uma empresa poderia incorrer em suas captações de fundos e deve remunerar no mínimo as expectativas de custos de capital dos investidores (SALAZAR, 2012).

O ROE representa a rentabilidade obtida sobre o capital investido pelos sócios da organização, apurado pela divisão do lucro líquido e patrimônio líquido (ASSAF NETO, 2012). A rentabilidade do capital próprio investido em uma organização deve ter uma rentabilidade superior aos rendimentos dos títulos de renda fixa (PADOVEZE, 2010).

\section{Procedimentos metodológicos}

\subsection{Classificação da pesquisa}

Esta pesquisa, quanto à abordagem do problema, caracteriza-se como quantitativa, pois emprega instrumentos matemáticos na coleta e tratamento dos dados, com a intenção de garantir maior precisão dos resultados e evitar distorções de análise e interpretação (VERGARA, 2006). Desta forma, o enfoque quantitativo foi utilizado para apuração dos cálculos das projeções e quocientes.

O procedimento técnico vincula-se ao estudo de caso, utilizando-se de pesquisa documental e entrevista não estruturada como métodos de obtenção de dados. O estudo de caso analisa um ou poucos objetos, de maneira que se permita o conhecimento amplo e detalhado (GIL, 2012). A documental foi utilizada para coleta dos dados na área financeira da organização e a entrevista para coletar informações operacionais, financeiras e estratégicas na elaboração do orçamento. Quanto aos fins, este estudo, vincula-se a pesquisa descritiva, pois descreve as especificidades da elaboração e análise do processo orçamentário.

\subsection{Unidade de análise e coleta dos dados}

A unidade de análise compreende uma indústria e comércio de esquadrias localizada na região do Vale do Taquari - RS. O enquadramento do porte é pequeno, segundo classificação do SEBRAE (2014), em função do número de funcionários, e a razão social desta indústria foi mantida em sigilo, atribuindo-se a denominação fictícia de Alfa. Os pesquisadores obtiveram autorização de acesso aos documentos e informações necessárias à elaboração do orçamento empresarial. Além disso, as entrevistas foram conduzidas de modo ético, respeitando as recomendações da literatura prévia sobre o método utilizado. Os participantes das entrevistas não estruturadas concordaram em participar da pesquisa voluntariamente.

A coleta dos dados com base na entrevista não estruturada foi realizada entre nov. 2016 e jan. 2017. As coletas das informações ocorreram sobre: a) Estrutura patrimonial: utilizadas na elaboração do balanço patrimonial do ano base de 2016; b) Estimativas de vendas e gastos esperados: para elaboração dos orçamentos de gastos com produção e despesas operacionais, a saber, investimentos, contratação de funcionários, distribuição de dividendos; e c) rentabilidade desejada: para compor os indicadores de custo e orçamento.

A utilização da pesquisa documental instrumentalizou a coleta dos controles do fluxo de caixa, relatórios de faturamento, notas fiscais de entrada e saída de mercadorias e produtos, balanços societários e registros de empregados. Além disso, em jan. 2016 coletou-se as informações sobre expectativas de inflação (IPCA) para os anos de 2017 a 2021, junto aos gestores da Alfa por meio da entrevista não estruturada.

\subsection{Tabulação, análise e discussão dos dados}


As peças orçamentárias foram organizadas anualmente, na seção dos resultados deste estudo, mas a apuração foi realizada mensalmente de 2017 a 2021. Na análise foram utilizadas as ferramentas de gestão, a saber, MC, PEE, PEF, PEC, MS, EBITDA, ROA e ROE, para avaliação do desempenho patrimonial, financeiro e econômico. As discussões ocorreram com base nos resultados obtidos e estes foram comparados com a fundamentação teórica.

O método escolhido para esta pesquisa pode apresentar limitações em relação a coleta dos dados, sendo assim, mesmo que a condução das entrevistas e as respostas dos entrevistados foram adequadas, pode ter existido algum tipo de viés nas respostas. Em relação à coleta de dados pelo método documental, os resultados devem ser observados com atenção e são válidos na extensão em que os relatórios fornecidos apresentam concordância com as normas contábeis vigentes. Os resultados e conclusões não podem ser generalizados, pois são específicos a indústria Alfa, apenas podem servir para fins de comparação à outras indústrias de esquadrias do mesmo porte.

\section{Resultados e análises}

\subsection{Elaboração e projeção do orçamento}

Esta seção apresenta os procedimentos utilizados na elaboração do orçamento de 2017 e suas projeções para os anos de 2018 até 2021. O processo orçamentário, neste estudo, iniciase na demonstração do BP de 2016 (TABELA 1).

Tabela 1 - Balanço Patrimonial de 2016, em R\$

\begin{tabular}{|c|c|c|c|}
\hline \multicolumn{4}{|c|}{ BALANÇO PATRIMONIAL } \\
\hline ATIVO CIRCULANTE & 178.389 & PASSIVO CIRCULANTE & 183.849 \\
\hline Disponibilidades & 24.856 & Fornecedores & 21.402 \\
\hline Contas a receber & 102.663 & Parcelamento impostos & 34.397 \\
\hline Clientes & 102.663 & Empréstimos bancários & 68.777 \\
\hline Impostos a recuperar & 4.687 & Encargos sociais & 34.284 \\
\hline Estoques & 46.183 & Salários a pagar & 14.311 \\
\hline Madeira & 26.915 & Pró-labore a pagar & 1.206 \\
\hline Ferragens & 19.267 & INSS a recolher & 3.715 \\
\hline ATIVO NÃO CIRCULANTE & 745.718 & FGTS a pagar & 9.469 \\
\hline Imobilizado & 745.718 & Contribuição sindical & 5.581 \\
\hline Prédios & 200.000 & Encargos fiscais & 24.988 \\
\hline Máquinas e equipamentos & 400.000 & Imposto simples a pagar & 24.988 \\
\hline Veículos & 77.263 & PASSIVO NÃO CIRCULANTE & 111.763 \\
\hline Ferramentas & 30.000 & Parcelamento impostos & 95.819 \\
\hline Computadores e periféricos & 4.500 & Empréstimos & 15.943 \\
\hline \multirow[t]{3}{*}{ Consórcio contemplado } & 33.954 & PATRIMONIO LÍQUIDO & 628.494 \\
\hline & & Capital Social & 592.494 \\
\hline & & Reservas de capital & 36.000 \\
\hline TOTAL DO ATIVO & 924.107 & TOTAL DO PASSIVO & 924.107 \\
\hline
\end{tabular}

Com base nas informações da Tabela 1, elaboraram-se as peças orçamentárias referentes às vendas, produção e matérias primas, mão de obra direta, custos indiretos de produção, despesas operacionais, investimentos, depreciação, fluxo de caixa e as projeções das demonstrações financeiras. $\mathrm{O}$ orçamento de vendas representa as expectativas de faturamento de produtos da Alfa (TABELA 2).

Tabela 2 - Orçamento de vendas, em RS

\begin{tabular}{llllll} 
DESCRIÇÃO & 2017 & 2018 & 2019 & 2020 & 2021 \\
\hline
\end{tabular}




\begin{tabular}{lrrrrr}
\hline Janela Veneziana & 334.347 & 363.972 & 395.023 & 498.914 & 577.398 \\
Vitrô de correr & 109.536 & 119.241 & 129.414 & 163.450 & 189.162 \\
Vitrômaximar & 48.972 & 53.311 & 57.859 & 73.076 & 84.571 \\
Porta interna & 606.144 & 659.852 & 716.145 & 904.491 & 1.046 .777 \\
Porta externa & 107.160 & 116.655 & 126.607 & 159.904 & 185.059 \\
Porta interna de correr & 41.442 & 45.114 & 48.963 & 61.841 & 71.569 \\
Portão garagem & 248.292 & 270.292 & 293.351 & 370.502 & 428.786 \\
Porta janela veneziana & 120.120 & 130.763 & 141.919 & 179.243 & 207.440 \\
Porta externa lambri & 62.898 & 68.471 & 74.312 & 93.856 & 108.621 \\
Marco Liso & 15.732 & 17.125 & 18.587 & 23.475 & 27.168 \\
\hline Vendas Totais & 1.694 .643 & 1.844 .801 & 2.002 .183 & 2.528 .757 & 2.926 .556 \\
\hline Crescimento anual das vendas totais ${ }^{*}$ & - & $8,86 \%$ & $8,53 \%$ & $26,30 \%$ & $15,73 \%$ \\
\hline Fonto
\end{tabular}

Fonte: Dados da pesquisa

* O crescimento anual das receitas foi apurado com base na seguinte equação:

Percentagem de crescimento das vendas $=\frac{\text { Valor Final }- \text { Valor Inicial }}{\text { Valor Inicial }} \times 100$

Nas projeções das vendas de 2018 a 2021 foram estimados incrementos das vendas de $3,36 \% ; 3,03 \% ; 20,80 \%$ e $10,23 \%$, respectivamente. Estes percentuais de crescimento foram coletados por meio de entrevistas não estruturadas com os administradores da Alfa. Além deste crescimento, os entrevistados também informaram um reajuste anual nos preços de 5,50\% a.a. com base no IPCA médio para fins de atualização monetária.

O percentual de crescimento anual das vendas totais é variável e está adequado as características específicas do consumo/mercado da Alfa (TABELA 2). Este crescimento ocorre em função das múltiplas finalidades do orçamento empresarial e este pode ser distinto entre as empresas, e assim, deve moldar-se a necessidade de cada empresa, o que também é defendido por Blumentritt (2006). Neste sentido, estima-se um incremento total do faturamento no período de 2017 a 2021 de 72,7\% (TABELA 2). Este incremento é reflexo da ampliação da estrutura produtiva da Alfa.

Após a realização do orçamento de vendas realiza-se o orçamento de produção e matéria prima (TABELA 3).

Tabela 3 - Orçamento de consumo de matérias primas, em R\$

\begin{tabular}{lrrrrr}
\hline \multicolumn{1}{c}{ DESCRIÇÃO } & 2017 & 2018 & 2019 & 2020 & 2021 \\
\hline Janela Veneziana & 167.928 & 182.808 & 198.404 & 250.584 & 290.003 \\
Vitrô de correr & 36.746 & 40.002 & 43.415 & 54.833 & 63.459 \\
Vitrômaximar & 16.060 & 17.483 & 18.975 & 23.966 & 27.736 \\
Porta interna & 210.182 & 228.806 & 248.325 & 313.635 & 362.973 \\
Porta externa & 34.428 & 37.478 & 40.675 & 51.373 & 59.455 \\
Porta interna de correr & 13.904 & 15.136 & 16.427 & 20.747 & 24.011 \\
Portão garagem & 127.224 & 138.496 & 150.312 & 189.844 & 219.708 \\
Porta janela veneziana & 40.645 & 44.247 & 48.022 & 60.651 & 70.193 \\
Porta externa lambri & 20.684 & 22.517 & 24.438 & 30.865 & 35.720 \\
Marco Liso & 5.107 & 5.559 & 6.034 & 7.620 & 8.819 \\
\hline Consumo Total & 672.912 & 732.537 & 795.030 & 1.004 .123 & 1.162 .082 \\
\hline Fonte: Dados da pesquisa & & & & &
\end{tabular}

Fonte: Dados da pesquisa

Na elaboração das projeções de 2018 a 2021 foi considerado um reajuste de preços das matérias primas de acordo com o IPCA de 5,5\% e, além disso, um crescimento de 3,36\%; $3,03 \% ; 20,80 \%$ e $10,23 \%$, respectivamente, com base na entrevista não estruturada com os administradores da Alfa. Portanto, o crescimento do consumo de matérias primas no período de 2017 a 2021 também é de 72,7\% (TABELA 3).

No orçamento de mão de obra direta estão relacionados os gastos anuais com a utilização de pessoal diretamente associado as etapas produtivas (TABELA 4). 
Tabela 4 - Orçamento de mão de obra direta, em RS

\begin{tabular}{lrrrrr}
\multicolumn{1}{c}{ Descrição } & 2017 & 2018 & 2019 & 2020 & 2021 \\
\hline Total Mão de Obra Direta & $\mathbf{4 3 9 . 0 0 8}$ & $\mathbf{4 7 2 . 2 0 0}$ & $\mathbf{5 6 2 . 5 2 4}$ & $\mathbf{6 6 1 . 1 2 7}$ & $\mathbf{7 1 0 . 9 8 8}$ \\
Proventos & $\mathbf{3 2 1 . 6 4 6}$ & $\mathbf{3 4 6 . 3 1 7}$ & $\mathbf{4 1 3 . 0 8 4}$ & $\mathbf{4 8 6 . 0 0 1}$ & $\mathbf{5 2 3 . 2 7 7}$ \\
Salário Bruto & 321.646 & 346.317 & 413.084 & 486.001 & 523.277 \\
Encargos Sociais & $\mathbf{9 3 . 2 7 7}$ & $\mathbf{1 0 0 . 4 3 1}$ & $\mathbf{1 1 9 . 7 9 4}$ & $\mathbf{1 4 0 . 9 4 0}$ & $\mathbf{1 5 1 . 7 5 0}$ \\
$1^{\circ}$ salário & 26.803 & 28.859 & 34.423 & 40.500 & 43.606 \\
Férias + 1/3 & 35.738 & 38.479 & 45.898 & 54.000 & 58.141 \\
FGTS & 30.735 & 33.092 & 39.472 & 46.440 & 50.002 \\
Benefícios & $\mathbf{2 4 . 0 8 3}$ & $\mathbf{2 5 . 4 5 1}$ & $\mathbf{2 9 . 6 4 5}$ & $\mathbf{3 4 . 1 8 5}$ & $\mathbf{3 5 . 9 6 0}$ \\
Vale Transporte & 5.016 & 5.301 & 6.174 & 7.118 & 7.487 \\
Vale Almoço & 17.556 & 18.554 & 21.614 & 24.925 & 26.220 \\
Seguro de Vida & 1.511 & 1.596 & 1.857 & 2.141 & 2.252 \\
\hline Fon
\end{tabular}

Fonte: Dados da pesquisa

No orçamento de mão de obra direta foram orçados 19 funcionários, além de gastos com proventos, benefícios concedidos e encargos sociais. Os proventos foram reajustados no mês de maio de cada ano com base na média dos últimos três dissídios coletivos do Sindicato das Indústrias da Construção Civil do Vale do Taquari, de 7,67\% (este percentual não se altera de forma significativa), e os benefícios foram reajustados pelo IPCA médio de 5,5\%. No ano de 2019, em virtude dos projetos de investimentos em infraestrutura, foi orçada a contratação de quatro novos funcionários com base nas informações do gestores da Alfa.

O orçamento de custos indiretos de produção, com exceção da depreciação, foi reajustado com base no IPCA médio (TABELA 5).

Tabela 5 - Orçamento dos custos indiretos de produção, em R\$

\begin{tabular}{lrrrrr}
\multicolumn{1}{c}{ Descrição } & 2017 & 2018 & 2019 & 2020 & 2021 \\
\hline Energia elétrica & 18.300 & 19.631 & 20.995 & 24.307 & 26.853 \\
Água consumo humano & 249 & 263 & 277 & 291 & 307 \\
Manutenção em máquinas & 4.400 & 4.650 & 4.900 & 5.157 & 5.426 \\
Manutenção em prédios & 2.400 & 2.536 & 2.672 & 2.813 & 2.959 \\
Primeiros socorros & 600 & 634 & 668 & 703 & 739 \\
Lubrificantes & 440 & 472 & 504 & 584 & 645 \\
Correias & 410 & 439 & 470 & 544 & 601 \\
Afiação de máquinas & 2.650 & 2.842 & 3.040 & 3.520 & 3.888 \\
Limpeza e higiene & 600 & 634 & 668 & 703 & 739 \\
Fretes & 6.700 & 7.187 & 7.687 & 8.899 & 9.831 \\
Destinação de resíduos & 450 & 475 & 501 & 527 & 554 \\
Depreciação & 51.916 & 54.000 & 61.000 & 68.000 & 68.000 \\
\hline Total & $\mathbf{8 9 . 1 1 5}$ & $\mathbf{9 3 . 7 6 7}$ & $\mathbf{1 0 3 . 3 8 6}$ & $\mathbf{1 1 6 . 0 5 3}$ & $\mathbf{1 2 0 . 5 4 8}$ \\
\hline
\end{tabular}

Fonte: Dados da pesquisa

No orçamento das despesas operacionais foi listado o gasto que não está diretamente vinculados ao processo produtivo e segmentados como despesas de vendas, administrativas, financeiras e tributárias (TABELA 6).

Tabela 6 - Orçamento de despesas operacionais, em RS

\begin{tabular}{lrrrrr}
\hline \multicolumn{1}{c}{ Descrição } & 2017 & 2018 & 2019 & 2020 & 2021 \\
\hline DESPESAS COM VENDAS & $\mathbf{9 4 . 1 1 8}$ & $\mathbf{1 0 3 . 5 0 9}$ & $\mathbf{1 1 0 . 4 9 1}$ & $\mathbf{1 2 6 . 9 7 5}$ & $\mathbf{1 6 1 . 4 7 2}$ \\
Celular & 3.890 & 4.173 & 4.463 & 5.167 & 5.708 \\
Combustível & 32.200 & 34.542 & 36.943 & 42.771 & 47.249 \\
Pedágios & 620 & 655 & 690 & 726 & 764 \\
Patrocínios & 200 & 211 & 222 & 234 & 246 \\
Manutenção de veículos & 7.900 & 8.349 & 8.797 & 9.259 & 9.742
\end{tabular}




\begin{tabular}{|c|c|c|c|c|c|}
\hline Seguro de veículo & 4.955 & 5.237 & 5.518 & 5.808 & 9.212 \\
\hline IPVA & 3.452 & 3.785 & 3.989 & 4.198 & 5.917 \\
\hline ANTT & 569 & 601 & 633 & 666 & 1.361 \\
\hline Aluguel apartamento & 4.560 & 4.819 & 5.078 & 5.344 & 5.623 \\
\hline Almoço & 9.350 & 10.030 & 10.727 & 12.419 & 13.720 \\
\hline Inadimplência & 22.369 & 24.351 & 26.428 & 33.379 & 38.630 \\
\hline Depreciação & 4.052 & 6.752 & 6.998 & 6.998 & 23.295 \\
\hline DESPESAS ADMINISTRATIVAS & 164.469 & $\mathbf{1 7 4 . 2 6 5}$ & 184.214 & 194.576 & 205.482 \\
\hline Depreciação & 2.500 & 2.500 & 2.500 & 2.500 & 2.500 \\
\hline CDL e Sindicatos & 816 & 862 & 908 & 956 & 1.006 \\
\hline Escritório contabilidade & 6.600 & 6.975 & 7.350 & 7.736 & 8.139 \\
\hline Correios & 605 & 639 & 673 & 709 & 746 \\
\hline Tabelionatos & 420 & 443 & 467 & 492 & 517 \\
\hline Assessoria jurídica & 1.200 & 1.268 & 1.336 & 1.406 & 1.479 \\
\hline Cursos & 480 & 507 & 534 & 562 & 591 \\
\hline Assessoria administrativa & 996 & 1.052 & 1.109 & 1.167 & 1.228 \\
\hline Manutenção de veículos & 580 & 613 & 645 & 679 & 715 \\
\hline IPVA & 750 & 792 & 835 & 879 & 924 \\
\hline Seguro veículo & 1.092 & 1.154 & 1.216 & 1.280 & 1.347 \\
\hline Combustível & 1.770 & 1.870 & 1.971 & 2.074 & 2.182 \\
\hline Internet & 720 & 760 & 801 & 843 & 887 \\
\hline Água & 120 & 126 & 133 & 140 & 147 \\
\hline Licença ambiental & 600 & 634 & 668 & 703 & 739 \\
\hline Material de escritório & 1.050 & 1.109 & 1.169 & 1.230 & 1.294 \\
\hline Material de limpeza & 710 & 750 & 790 & 832 & 875 \\
\hline Taxa marcenaria e IPTU & 450 & 475 & 501 & 527 & 554 \\
\hline Tarifas bancárias & 1.672 & 1.767 & 1.862 & 1.959 & 2.061 \\
\hline Celular e telefone fixo & 2.504 & 2.646 & 2.788 & 2.934 & 3.087 \\
\hline Confraternização & 1.200 & 1.268 & 1.336 & 1.406 & 1.479 \\
\hline Cadastro florestal & 345 & 364 & 384 & 404 & 425 \\
\hline Salário administrativo & 22.704 & 24.445 & 26.320 & 28.339 & 30.513 \\
\hline $13^{\circ}$ salário & 1.892 & 2.037 & 2.193 & 2.361 & 2.542 \\
\hline Férias e $1 / 3$ & 2.522 & 2.716 & 2.924 & 3.148 & 3.390 \\
\hline FGTS & 2.169 & 2.335 & 2.515 & 2.708 & 2.915 \\
\hline Pró-labore & 108.000 & 114.145 & 120.274 & 126.589 & 133.184 \\
\hline DESPESAS FINANCEIRAS & 31.054 & 19.930 & 30.101 & 22.157 & 19.007 \\
\hline Tarifas emprés. bancários & 556 & 120 & 5.120 & 120 & 120 \\
\hline Juros de empréstimos & 30.497 & 19.810 & 24.981 & 22.037 & 18.887 \\
\hline DESPESAS TRIBUTÁRIAS & 150.144 & 183.421 & 209.579 & 269.422 & $\mathbf{3 3 2 . 5 3 7}$ \\
\hline Imposto do simples nacional & 150.144 & 183.421 & 209.579 & 269.422 & 332.537 \\
\hline Total de despesas operacionais & 439.786 & 481.127 & 534.386, & 613.132 & 718.500 \\
\hline
\end{tabular}

Fonte: Dados da pesquisa

As despesas com vendas, exceto depreciação e inadimplência, foram projetadas com base no IPCA médio e a inadimplência foi fixada em $2 \%$ sobre o volume de vendas a prazo, conforme estimativas dos gestores. O orçamento de despesas de vendas, no período de 2017 a 2021, apresenta um aumento de 71,6\% (TABELA 6), ou seja, um percentual aproximado da estimativa de incremento total do faturamento, no mesmo período, de 72,7\% (TABELA 2). $\mathrm{O}$ orçamento de despesas administrativas apresenta um aumento de $24,9 \%{ }^{1}$, abaixo da estimativa de incremento total do faturamento, indicando ampliação na eficiência operacional da Alfa. As despesas financeiras apresentam uma diminuição de $38,8 \% \%^{2}$ (TABELA 6), indicando maior eficiência na utilização de recursos financeiros.

\footnotetext{
${ }^{1}$ Percentagem de crescimento das despesas administrativas $=\frac{\text { Valor Final }- \text { Valor Inicial }}{\text { Valor Inicial }} \times 100$

2 Percentagem de crescimento das despesas financeiras $=\frac{\text { Valor Final }- \text { Valor Inicial }}{\text { Valor Inicial }} \times 100$ 
$\mathrm{O}$ orçamento de despesas tributárias apresenta um aumento de $121,5 \%$, superior à estimativa de incremento total do faturamento, porém não afeta o fluxo de caixa da empresa. Este aumento dos tributos ocorreu em função das categorias de alíquotas definidas pela Receita Federal do Brasil, pois a alíquota dos tributos aumenta conforme o volume do faturamento. Além disto, cabe destacar que o total do tributo em 2021 corresponde a 11,3\% do faturamento da Alfa, ou seja, está dentro da normalidade operacional.

No orçamento de investimentos foram detalhados os gastos com máquinas, prédios e veículos (TABELA 7). A administração espera reflexos do investimento no aumento de faturamento a partir de 2020, projetando um aumento nos volumes de vendas de $20 \%$ em 2020 e de $10 \%$ em 2021, que pode ser visto na Tabela 2 . Este investimento será realizado através da contratação de financiamento bancário.

Tabela 7 - Investimento em máquinas, em R\$

\begin{tabular}{lrrrr}
\hline Investimento & Junho/2017 & Fevereiro/2018 & Janeiro/2019 & Janeiro/2021 \\
\hline Máquinas & 50.000 & & 100.000 & \\
Prédios & & 34.990 & 150.000 & 156.478 \\
Veículos & & & \\
\hline
\end{tabular}

Fonte: Dados da pesquisa

Em decorrência da previsão de aumento do faturamento, a administração projeta adquirir um caminhão para auxiliar nas entregas aos clientes em janeiro de 2021, caso tiver disponibilidade de recursos em caixa (TABELA 9). O orçamento de depreciação foi realizado com base na vida útil e o valor residual dos ativos depreciáveis (TABELA 8).

Tabela 8 - Orçamento com de depreciação

\begin{tabular}{lrrrr}
\multicolumn{1}{c}{ Descrição } & $\begin{array}{r}\text { Valor ano base } \\
\mathbf{2 0 1 6}(\mathbf{R} \mathbf{)})\end{array}$ & $\begin{array}{c}\text { Vida útil } \\
\text { (anos) }\end{array}$ & $\begin{array}{r}\text { Depreciação } \\
\text { mensal (R\$) }\end{array}$ & $\begin{array}{c}\text { Valor } \\
\text { residual (R\$) }\end{array}$ \\
\hline Prédios & 200.000 & 25 & 500 & 50.000 \\
Máquinas e equipamentos & 400.000 & 10 & 3.333 & - \\
Ferramentas & 30.000 & 10 & 250 & - \\
Computadores e periféricos & 4.500 & 5 & 75 & - \\
Caminhão & 45.000 & 5 & 250 & 30.000 \\
Courier & 12.263 & 5 & 87 & 7.000 \\
Fiesta & 20.000 & 5 & 133 & 12.000 \\
Investimento em máquinas -2017 & 50.000 & 10 & 416 & - \\
Investimento em prédio -2019 & 150.000 & 25 & 333 & 50.000 \\
Investimento em máquinas -2019 & 100.000 & 10 & 833 & - \\
Saveiro - 2018 & 34.990 & 5 & 333 & 15.000 \\
Caminhão -2021 & 121.488 & 5 & 1.358 & 40.000 \\
\hline Fonte: Dados da pesquisa
\end{tabular}

Fonte: Dados da pesquisa

Após a elaboração dos orçamentos parciais realizou-se as projeções do fluxo de caixa, da DRE e do BP. Sendo assim, o orçamento do fluxo de caixa foi projetado pelo método direto (TABELA 9).

Tabela 9 - Orçamento do fluxo de caixa, em RS

\begin{tabular}{lrrrrr}
\hline \multicolumn{1}{c}{ Descrição } & $\mathbf{2 0 1 7}$ & $\mathbf{2 0 1 8}$ & $\mathbf{2 0 1 9}$ & $\mathbf{2 0 2 0}$ & $\mathbf{2 0 2 1}$ \\
\hline SALDO INICIAL & $\mathbf{2 4 . 8 5 6}$ & $\mathbf{2 8 9}$ & $\mathbf{5 9 . 3 5 3}$ & $\mathbf{7 8 . 2 6 6}$ & $\mathbf{1 6 5 . 6 1 1}$ \\
ENTRADAS & $\mathbf{1 . 6 6 4 . 4 4 1}$ & $\mathbf{1 . 8 1 7 . 3 7 4}$ & $\mathbf{2 . 2 1 0 . 8 7 2}$ & $\mathbf{2 . 4 4 5 . 5 8 5}$ & $\mathbf{2 . 8 5 0 . 3 1 0}$ \\
Recebimento de clientes & 1.612 .641 & 1.806 .251 & 1.960 .872 & 2.445 .585 & 2.850 .310$, \\
Entradas financeiras & 51.800 & - & 250.000 & - & - \\
Venda de veículo & - & 11.123 & - & - & - \\
SAÍDAS & $\mathbf{1 . 6 8 9 . 0 0 9}$ & $\mathbf{1 . 7 5 8 . 3 1 0}$ & $\mathbf{2 . 1 9 1 . 9 5 9}$ & $\mathbf{2 . 3 5 8 . 2 4 0}$ & $\mathbf{2 . 9 5 6 . 4 8 8}$ \\
Folha, Encargos e Benefícios & 561.790 & 614.785 & 705.657 & 820.179, & 879.148 \\
Gastos industriais & 710.788 & 770.130 & 1.085 .137 & 1.044 .550 & 1.208 .869
\end{tabular}




\author{
Despesas com vendas \\ Despesas administrativas \\ Despesas financeiras \\ Despesas tributárias \\ Distribuição de lucros
}

\begin{tabular}{rrrrr}
67.696 & 73.441 & 77.064 & 86.597 & 221.034 \\
30.262 & 26.084 & 27.485 & 28.928, & 30.435 \\
159.227 & 93.347 & 88.813 & 114.660 & 111.510 \\
159.244 & 180.520, & 207.800 & 263.323 & 325.489 \\
- & - & - & - & 220.000 \\
$\mathbf{2 8 9}$ & $\mathbf{5 9 . 3 5 3}$ & $\mathbf{7 8 . 2 6 6}$ & $\mathbf{1 6 5 . 6 1 1}$ & $\mathbf{1 9 . 4 3 3}$ \\
\hline
\end{tabular}

$\frac{\text { SALDO FINAL }}{\text { Fonte: Dados da pesquisa }}$

O orçamento empresarial elaborado no período de 2017 a 2021 gera excedente de caixa (TABELA 9). Ademais, em janeiro de 2021, em virtude da estimativa de excedente de caixa, foi orçado o desembolso financeiro para aquisição de veículo. A DRE foi elaborada pelo método de custeio variável (TABELA 10), pois este custeio não utiliza-se de critérios de rateio dos custos e despesas fixas.

Tabela 10 - DRE projetada, em R\$

\begin{tabular}{lrrrrr}
\hline DESCRIÇÃO & $\mathbf{2 0 1 7}$ & $\mathbf{2 0 1 8}$ & $\mathbf{2 0 1 9}$ & \multicolumn{1}{c}{$\mathbf{2 0 2 0}$} & $\mathbf{2 0 2 1}$ \\
\hline RECEITAS OPERACIONAIS & 1.694 .643 & 1.844 .801 & 2.002 .183 & 2.528 .757 & 2.926 .556 \\
\hline (-) Tributos sobre vendas & 150.144 & 183.421 & 209.579 & 269.422 & 332.537 \\
\hline RECEITAS GERENCIAIS & 1.544 .499 & 1.661 .380 & 1.792 .603 & 2.259 .334 & 2.594 .018 \\
\hline (-) Custos dos Produtos Vendidos & 672.912 & 732.537 & 795.030 & 1.004 .123 & 1.162 .082 \\
\hline MARGEM DE CONTRIBUIÇÃO & 871.587 & 928.842 & 997.573 & 1.255 .210 & 1.431 .936 \\
\hline (-) Despesas de Produção Fixas & 528.123 & 565.968 & 665.910 & 777.180 & 831.536 \\
\hline (-) Despesas de Vendas & 94.118 & 103.509 & 110.491 & 126.975 & 161.472 \\
\hline (-) Despesas Administrativas & 164.469 & 174.265 & 184.214 & 194.576 & 205.482 \\
\hline (-) Despesas Financeiras Líquidas & 31.054 & 19.930 & 30.101 & 22.157 & 19.007 \\
\hline RESULTADO OPERACIONAL & 53.821 & 65.168 & 6.854 & 134.321 & 214.436 \\
\hline Fon
\end{tabular}

Fonte: Dados da pesquisa

$\mathrm{Na}$ DRE as receitas operacionais são compostas pelo orçamento de vendas (TABELA 2), os tributos sobre vendas são compostas pelo orçamento de despesas tributárias (TABELA 6), os custos dos produtos vendidos são formados com base no orçamento de consumo de matérias primas (TABELA 3), as despesas fixas de produção são formadas pelos orçamentos de gastos com mão de obra (TABELA 4), o orçamento de custos indiretos de produção e as despesas de vendas são compostas pelo orçamento de despesas com vendas, as despesas administrativas são formadas com base no orçamento de despesas administrativas e as despesas financeiras líquidas são formadas pelos gastos detalhados no orçamento de despesas financeiras (TABELA 6).

A análise da projeção da DRE revela uma lucratividade ${ }^{3}$ de 2017 a 2021 de 3,2\%, 3,5\%, $0,3 \%, 5,3 \%$ e $7,3 \%$, respectivamente (TABELA 10 ). A lucratividade é crescente no período analisado, exceto em 2019, no qual ocorreu o investimento de $\mathrm{R} \$ 250.000,00$ relativos a prédios e máquinas.

O BP de 2016 (TABELA 1) foi utilizado como base na elaboração do BP de 2017 a 2021 (TABELA 11).

Tabela 11 - Balanço Patrimonial, em RS

\begin{tabular}{|c|c|c|c|c|c|c|}
\hline & Abertura & 2017 & 2018 & 2019 & 2020 & 2021 \\
\hline ATIVO CIRCULANTE & 178.389 & 208.387 & 285.293 & 322.907 & 472.820 & 373.908 \\
\hline Disponibilidades & 24.856 & 289 & 59.353 & 78.266 & 165.611 & 19.433 \\
\hline Contas a receber & 102.663 & 162.296 & 176.494 & 191.376 & 241.168 & 278.783 \\
\hline Impostos a recuperar & 4.687 & 4.687 & 4.687 & 4.687 & 4.687 & 4.687 \\
\hline Estoques & 46.183 & 41.115 & 44.758 & 48.577 & 61.353 & 71.004 \\
\hline
\end{tabular}

\footnotetext{
${ }^{3}$ Lucratividade $=\frac{\text { Resultado Operacional }}{\text { Receitas Operacionais }} \times 100$
} 


\begin{tabular}{lrrrrrr}
\hline ATIVO NÃO CIRCULANTE & 745.718 & 737.248 & 663.908 & 843.410 & 765.912 & 793.604 \\
\hline Imobilizado & 745.718 & 737.248 & 663.908 & 843.410 & 765.912 & 793.604 \\
\hline TOTAL DO ATIVO & 924.107 & 945.636 & 949.202 & 1.166 .317 & 1.238 .732 & 1.167 .513 \\
\hline PASSIVO CIRCULANTE & 183.849 & 198.174 & 159.568 & 248.046 & 278.642 & 284.415 \\
\hline Fornecedores & 21.402 & 65.657 & 71.475 & 77.573 & 97.974 & 113.387 \\
\hline Parcelamento Impostos & 34.397 & 32.597 & 21.074 & 21.074 & 21.074 & - \\
\hline Empréstimos & 68.777 & 40.820 & 1.924 & 71.429 & 71.429 & 71.429 \\
\hline Encargos Sociais & 34.284 & 43.209 & 46.305 & 57.401 & 61.497 & 65.884 \\
\hline Encargos fiscais & 24.988 & 15.888 & 18.789 & 20.567 & 26.666 & 33.714 \\
\hline PASSIVO NÃO CIRCULANTE & 111.763 & 65.146 & 42.148 & 163.931 & 71.428 & - \\
\hline Parcelamento de Impostos & 95.819 & 63.222 & 42.148 & 21.074 & - & - \\
\hline Empréstimos & 15.943 & 1.923 & & 142.857 & 71.428 & - \\
\hline PATRIMÔNIO LÍQUIDO & 628.494 & 682.316 & 747.485 & 754.339 & 888.661 & 883.098 \\
\hline Capital social & 592.494 & 592.494 & 592.494 & 592.494 & 592.494 & 592.494 \\
\hline Reservas de capital & 36.000 & 36.000 & 36.000 & 36.000 & 36.000 & 36.000 \\
\hline Reserva de lucros & - & 53.821 & 118.990 & 125.844 & 260.166 & 254.603 \\
\hline TOTAL DO PASSIVO & 924.107 & 945.636 & 949.202 & 1.166 .317 & 1.238 .732 & 1.167 .513 \\
\hline Fonte: Dados da pesquisa & & & & & &
\end{tabular}

O BP revela-se saudável em função do crescimento do valor do patrimônio líquido que é o valor residual da Alfa. Além disso, a Alfa teve um crescimento dos bens e direitos acima do valor das obrigações. Esta situação revela que o orçamento refletiu de forma eficiente a agregação do valor patrimonial e fortalece a validação do orçamento.

\subsection{Análise das projeções do orçamento}

A avaliação da eficácia do orçamento realizou-se por meio da MS, pontos de equilíbrio, MC, EBITDA, ROA e ROE (TABELA 12).

Tabela 12 - Análise das projeções

\begin{tabular}{lrrrrr}
\hline Análises & $\mathbf{2 0 1 7}$ & $\mathbf{2 0 1 8}$ & $\mathbf{2 0 1 9}$ & $\mathbf{2 0 2 0}$ & $\mathbf{2 0 2 1}$ \\
\hline MC Total (R\$) & 871.587 & 928.842 & 997.573 & 1.255 .210 & 1.431 .936 \\
\hline MC Total (\%) & 51,4 & 50,3 & 49,8 & 49,6 & 48,9 \\
\hline PEC (R\$) & 1.589 .994 & 1.717 .046 & 1.989 .393 & 2.259 .857 & 2.489 .774 \\
\hline PEE (R\$) & 1.788 .989 & 1.939 .954 & 2.216 .604 & 2.528 .606 & 2.772 .933 \\
\hline PEF (R\$) & 1.476 .311 & 1.591 .295 & 1.847 .831 & 2.103 .611 & 2.297 .963 \\
\hline MS (R\$) & 104.649 & 127.754 & 12.789 & 268.899 & 436.781 \\
\hline MS (\%) & 6,2 & 6,9 & 0,6 & 10,6 & 14,9 \\
\hline EBITDA (R\$) & 143.345 & 148.352 & 107.454 & 233.977 & 327.240 \\
\hline EBITDA (\%) & 9,3 & 8,9 & 6,0 & 10,4 & 12,6 \\
\hline ROA (\%) & 9,1 & 9,0 & 3,5 & 13,0 & 19,1 \\
\hline ROE (\%) & 8,2 & 9,1 & 0,9 & 16,4 & 23,7 \\
\hline Fonte: Das & & & & &
\end{tabular}

Fonte: Dados da pesquisa

A MC é suficiente para pagar as despesas e gerar lucro. Além disso, conforme estudo de Silva (2010) realizado em indústria de móveis em Sapiranga-RS, apurou uma MC de 31\%, comparando os estudos constata-se que a MC da Alfa é maior. O volume de vendas totais no período de 2017 a 2021 excedem o PEC e PEF, indicando que as receitas projetadas são suficientes para cobrir os gastos totais. No entanto, as vendas totais apuradas nos anos de 2017 , 2018 e 2019 não atingem o PEE, indicando que o faturamento projetado neste período não será suficiente para proporcionar o resultado desejado pela administração, o qual é de $15 \%$ sobre o patrimônio líquido. Neste caso, torna-se prudente revisar se o aumento estipulado pelos administradores do volume de vendas é suficiente para suportar um resultado de $15 \%$ sobre o patrimônio Líquido. Portanto, sugere-se avaliar se o valor investido em 2019 está rentabilizando 
adequadamente, caso contrário, solicita-se revisar o aumento da capacidade produtiva no período que pode ser insuficiente.

A MS em 2017, 2018 e 2019 possui as menores margens no período orçado, e conforme entrevista com os gestores, é remota a possibilidade de aumentar este indicador devido às limitações estruturais da Alfa. Isso demonstra a importância dos investimentos projetados em 2019, que possibilitarão à empresa aumentar sua MS para 10,6\% em 2020 e 14,9\% em 2021.

O EBITDA revela nos anos 2017 (9,3\%), 2018 (8,9\%) e 2019 (6,0\%) uma queda no potencial de geração de caixa e diminuição de eficiência econômica. Já em 2020 (10,4\%) e $2021(12,6 \%)$ o EBITDA é crescente em relação ao primeiro período (2017 a 2019). Este comportamento pode ser explicado em função dos investimentos planejados para 2019 que podem refletir devem aumentar sua produtividade tornando-se economicamente mais eficiente.

O ROE nos anos de 2020 e 2021, no período posterior aos investimentos, supera a taxa SELIC de 10,5\% a.a. Portanto, demonstra remunerar adequadamente o capital investido e sua aplicação na ampliação da estrutura física.

\subsection{Discussão dos resultados}

Os resultados referente a elaboração e análise do orçamento empresarial na Alfa instigam algumas reflexões, a saber: a) o orçamento empresarial versus tamanho da empresa; b) a condução na elaboração do orçamento empresarial; c) as formas de utilização das informações orçamento; e d) as dificuldades no orçamento empresarial.

O tamanho da organização deve ser observado no momento da elaboração do orçamento empresarial, pois possui características específicas que impactam no processo de orçamentação. As MPE se caracterizam pela estrutura organizacional e divisão do trabalho de forma simplificada, a supervisão é direta e centralizada nos proprietários, as decisões são atribuídas aos proprietários, os treinamentos de mão de obra são mínimos, os recursos financeiros e o tempo disponível são escassos, entre outros (MINTZBERG, 2003). Sendo assim, o orçamento em MPE deve ser elaborado de forma simplificada, no tempo mínimo possível e o menor recurso financeiro necessário, também defendido por Orlando (2009) e Waal, HermkensJanssen e Van De Ven (2011). Ou seja, a estrutura do orçamento deve observar a premissa do custo benefício que gera à organização.

A condução na elaboração do orçamento empresarial em MPE deve ser realizada observando-se o alinhamento entre o planejamento estratégico e o orçamentário. Blumentritt (2006) enfatiza que o desempenho global da organização pode ser melhorado quando estes planejamentos são usados com coerência e que sua desconexão dificulta a implantação do orçamento e podem não ser suportadas pelos recursos financeiros disponíveis. Além disso, há a necessidade de uma visão holística e integrada no planejamento orçamentário em relação as áreas da organização.

O orçamento deve ser flexível e ajustar-se às condições do mercado e da organização ao longo do período, sendo assim, pode sofrer alterações e ajustes em relação aos valores e estratégias para condução ou recondução empresarial. A principal fraqueza do orçamento relaciona-se a sua inflexibilidade, tornando-o incapaz de adaptar-se à ambientes com rápidas mutações (TAYLOR, 2009), portanto se torna desatualizado (LIBBY; LINDSEY, 2010).

Uma das dificuldades do orçamento empresarial relaciona-se a projeção de eventos futuros em ambientes competitivos, logo a flexibilidade do orçamento pode auxiliar neste processo, também corroborado por Vaznoniene (2012). As projeções no âmbito do orçamento empresarial, em especial, as vendas devem ser realizadas com cautela e prudencia, pois o viés do excesso de confiança e da heurística influenciam negativamente às projeções em PME, segundo Cassar e Gibson (2007) e Hakola (2011). 


\section{Conclusão}

A elaboração das diversas peças orçamentárias demonstrou a evolução na eficiência econômica da Alfa. Os resultados revelam que o faturamento apresentou incremento de 2017 a 2021 de $72,7 \%$, enquanto os gastos com mão de obra direta (62\%), custos indiretos de produção $(35,3 \%)$ e despesas operacionais $(63,4 \%)$ não aumentaram na mesma proporção. Este fato resultou no aumento do resultado operacional de $298,4 \%$, de $137,1 \%$ na lucratividade de produtos, de $35,5 \%$ no EBITDA e de $189,0 \%$ no ROE. Ademais, a MC anual média foi de 50\%, e as vendas orçadas atingiram os PEs apenas em 2020 e 2021.

Estes resultados enfatizam que a elaboração do orçamento, por exemplo, projetação do desempenho das receitas e dos gastos não é uma tarefa fácil, pois além de considerar as estratégias e informações passadas deve-se avaliar e traçar as futuras. A dificuldade deste processo reside em realizar as projeções que estejam adequadas à estrutura operacional, humana e financeira da Alfa e mister satisfazer os administradores por meio da lucratividade desejada.

A conclusão enfatiza que a elaboração do orçamento em conjunto com as análises demonstram que a Alfa, por meio desta ferramenta, pode planejar um aumento da eficiência econômica. Diante do exposto, observa-se com a elaboração deste orçamento que foi possível planejar uma evolução na eficiência econômica da Alfa, em especial, no período de 2020 e 2021. Neste período foi possível visualizar os reflexos dos investimentos planejados em infraestrutura no ano 2019 e reforçar seu potencial de benefício.

A sugestão é que a indústria Alfa utilize estas informações proporcionadas pela elaboração do orçamento em suas rotinas gerenciais, como direcionador de suas decisões. As sugestões para pesquisas futuras vinculam-se a realização do controle sobre o realizado e projetado para analisar as principais variáveis que possam interferir no processo orçamentário.

\section{Referências}

ASSAF NETO, A. Finanças corporativas e valor. 6. ed. São Paulo: Atlas. 2012.

BRUNI, A. L.; FAMÁ, R. Gestão de custos e formação de preços: com aplicações na calculadora HP $12 \mathrm{C}$ e Excel. 5. ed. São Paulo: Atlas. 2008.

BLUMENTRITT, T. Integrating strategic management and budgeting. Journal of business strategy, v. 27 , n. 6 , p. $73-79,2006$.

CASSAR, G.; GIBSON, B. Forecast rationality in small firms. Journal of Small Business Management, v. 45, n. 3, p. 283-302, 2007.

CHIAVENATO, I. Empreendedorismo: Dando asas ao espírito empreendedor. 2. ed. São Paulo: Saraiva. 2008.

CREPALDI, S. A. Curso básico de contabilidade de custos. 2. ed. São Paulo: Atlas. 2002.

CREPALDI, S. A. Contabilidade gerencial: teoria e prática. 6. ed. São Paulo: Atlas. 2012.

DAVILA, A.; FOSTER, G.; LI, M. Reasons for management control systems adoption: Insights from product development systems choice by early-stage entrepreneurial companies. Accounting, Organizations and Society, v. 34, n. 3-4, p. 322-347, 2009.

DORNELAS, J. C. A. Empreendedorismo: Transformando ideias em negócios. 4. ed. Rio de Janeiro: Elsevier. 2012. 
FREZATTI, F. Orçamento empresarial: planejamento e controle gerencial. 5. ed. São Paulo: Atlas. 2009.

GIL, A. C. Métodos e técnicas de pesquisa social. 6. ed. São Paulo: Atlas. 2012.

HAKOLA, M. Sales forecast rationality and small business reorganisation. International Journal of Management and Enterprise Development, v. 11, n. 2-4, p. 85-108, 2011.

HANSEN, S.; OTLEY, D.; VAN DER STEDE, W. Practice Developments in Budgeting: An Overview and Research Perspective. Journal of Management Accounting Research, v.15, p. 95-116, 2003.

HOPE, J.; FRASER, R. Who needs budgets? Harvard business review, v. 81, n. 2, p. 108-126, 2003.

KING, R.; CLARKSON, P. M.; WALLACE, S. Budgeting practices and performance in small healthcare businesses. Management Accounting Research, v. 21, p. 40-55, 2010.

LEONE, G. S. G. Curso de contabilidade de custos. 4. ed. São Paulo: Atlas. 2010.

LIBBY, T.; LINDSAY, M. Beyond budgeting or budgeting reconsidered? A survey of North-American budgeting practice. Management Accouting Research, v. 21, p. 56-75, 2010.

MARTINS, E. Contabilidade de custos. 9. ed. São Paulo: Atlas, 2009.

MARTH, A.; FEIL, A. A. Implantação do orçamento base zero na gestão de uma empresa de radiodifusão. Revista Eletrônica de Administração e Turismo, v. 5, n. 3, p. 489-507, 2014a.

MARTH, A.; FEIL, A. A. Orçamento corporativo: elaboração e análise de orçamento base zero para gestão de pequenas empresas. Destaques Acadêmicos, v. 6, n. 1, $2014 \mathrm{~b}$.

OLBERMANN, M. C.; FEIL, A. A.; SCHREIBER, D. A inserção e o exame do orçamento base zero em microempresa. Brazilian Journal of Management \& Innovation, v. 1, n. 2, p. 87-107, 2014.

ORLANDO, J. Turning budgeting pain into budgeting gain. Strategic finance, v. 90, n. 9, p. 47, 2009.

PADOVEZE, C. L. Planejamento orçamentário: texto e exercícios. São Paulo: Pioneira. 2005.

PADOVEZE, C. L. Orçamento empresarial: novos conceitos e técnicas. São Paulo: Pearson. 2009.

PADOVEZE, C. L. Contabilidade gerencial: um enfoque em sistema de informação contábil. 7. ed. São Paulo: Atlas. 2010.

SÁ, C. A. Orçamento empresarial: novas técnicas de elaboração e de acompanhamento. São Paulo: Atlas. 2014.

SALAZAR, G. T. Administração dos fluxos de caixa: teoria e prática: de acordo com as Leis $\mathrm{n}^{\circ}$ 11.638/2007, 11.941/2009 e normas emitidas pelo CPC. São Paulo: Atlas, 2012.

SANVICENTE, A. Z.; SANTOS, C. C. Orçamento na administração de empresas: planejamento e controle. 2. ed. São Paulo: Atlas. 2008.

Sebrae - Serviço Brasileiro de Apoio às Micro e Pequenas Empresas. Participação das Micro e Pequenas Empresas na Economia Brasileira. 2014. Disponível em: <https://m.sebrae.com.br/ 


\section{REAVI}

Sebrae/Portal\%20Sebrae/Estudos\%20e\%20Pesquisas/Participacao\%20das\%20micro\%20e\%20pequen as\%20empresas.pdf $>$. Acesso em 16 dez. 2017.

SEBRAE. Fatores Condicionantes e Taxa de Mortalidade das MPE. Disponível em: $<$ http://www.bibliotecas.sebrae.com.br/chronus/ARQUIVOS_CHRONUS/bds/bds.nsf/8F5BDE79736 CB99483257447006CBAD3/\$File/NT00037936.pdf>. Acesso em 16 set. 2016.

SEBRAE. Sobrevivência das Empresas no Brasil. 2013. Disponível em: < http://www.sebrae.com.br /Sebrae/Portal\%20Sebrae/Anexos/Sobrevivencia_das_empresas_no_Brasil=2013.pdf $>$. Acesso em 17 set 2016.

SILVA, J. F. Formação do preço de venda em indústria de móveis de Sapiranga. Novo Hamburgo. 2010.

SILVA, E. C. Como administrar o fluxo de caixa das empresas - guia de sobrevivência empresarial. 6. ed. São Paulo: Atlas. 2012.

TAYLOR, A. How strategic budgeting can control cost while improving performance. Journal of Corporate Accounting \& Finance, v. 20, n. 3, p. 53-58, 2009.

VAZNONIENE, M. Corporate budgets and their limitations: a case study of meat and poultry producers. Economics and Rural Development, v. 8, n. 2, p. 37-49, 2012.

VERGARA, S. C. Projetos e relatórios de pesquisa em administração. 7. ed. São Paulo: Atlas. 2006.

WAAL, A.; HERMKENS-JANSSEN, M.; VAN DE VEN, A. The evolutionary adoption framework: explaining the budgeting paradox. Journal of Accounting \& Organizational Change, v. 7, n. 4, p. 316-336, 2011.

WELSCH, G. A. Orçamento empresarial. 4. ed. São Paulo: Atlas. 2010. 